\title{
Recommendations for model identification for MPC of an all-Air HVAC system
}

\author{
Quinten Carton ${ }^{1, *}$, Bart Merema $^{1}$, and Hilde Breesch ${ }^{1}$ \\ ${ }^{1}$ KU Leuven, Department of Civil Engineering, Building Physics and Sustainable Design, Ghent Technology Campus, Belgium
}

\begin{abstract}
Rule-based control (RBC) strategies are often unable to execute the optimal control action, which leads to unnecessary energy consumption and suboptimal comfort. Model predictive control (MPC) is a dynamic control strategy for heating, ventilation and air-conditioning (HVAC) systems that is mostly more capable of performing optimal control actions. The identification process of predictive models is an essential aspect of MPC. However, this model identification process remains time consuming due to the large variation in buildings and systems. The aim of this paper is to determine guidelines to identify predictive grey-box models more time efficient, thus enhancing the applicability of MPC.

This paper focusses on a case study building equipped with an all-air HVAC system, which combines ventilation, heating and cooling. Making both temperature and $\mathrm{CO}_{2}$-concentration key parameters to predict. The grey-box model represents an open zone in a landscaped office, making the influence of neighbouring zones an additional challenge.

Different models for predicting the zone temperature and $\mathrm{CO}_{2}$-concentration are identified, evaluated and validated using CTSM-R. The following aspects are studied: the dataset size, the influence of neighbouring zones, the difference between winter and summer conditions, number of states and the prediction horizon. A three state RC-model with the implementation of the zone temperature of one neighbouring zone is preferred for predicting the indoor temperature with an acceptable prediction horizon of one day. However, this temperature model is not suitable during sunny periods. A simple model representing a mass balance obtains accurate predictions of the zone $\mathrm{CO}_{2}$-concentration for a timestep of 15 minutes. For both model types the utilization of 5-day datasets is favoured over 12-day datasets due to a shorter monitoring period, lower prediction error and an easier parameter convergence. The usage of 12-day datasets is only preferred when an accurate estimation of the thermal inertia is pursued.
\end{abstract}

\section{Introduction}

Control strategies are implemented in heating, ventilation and air-conditioning (HVAC) systems to reduce energy use. A control strategy has two contradictory objectives, i.e., minimizing the energy consumption while maximizing the occupants' comfort. Rule-based control (RBC) strategies are often unable to execute the optimal control action, which leads to unnecessary energy consumption [1]. Model predictive control (MPC) is a dynamic control strategy using predictive models and is more capable to achieve an optimal control action [2]. The identification process of predictive models is an essential part of MPC.

Three model structures can be identified, i.e., whitebox based on only the physical characteristics of a building, black-box models using exclusively data and grey-box models which combine physical parameters and data [2]. This paper will focus on grey-box models due to their feasibility for dynamic systems and their knowledge concerning the buildings thermal behaviour [3].

Although a general toolbox to identify grey-box models exists [4], the identification process stays time consuming [2]. This paper aims to determine guidelines for a more efficient grey-box model identification process by identifying, evaluating and validating multiple predictive models.

Most research regarding MPC focusses on hydronic systems and less on air-based systems [5]. Therefore, this paper will identify predictive models for an all-air HVAC system. This system type combines ventilation, heating and cooling. The control of this system type deals with an extra contradiction, i.e., ventilation and heating demand. As a result, a suitable MPC strategy should have accurate predictions of both room temperature and $\mathrm{CO}_{2}$-level to determine the optimal control action for the all-air system.

The grey-box model in this paper represents an open zone in a landscape office in a case study building. This leads to a supplementary challenge, i.e., how to implement the influence of neighbouring zones in the predictive model?

The results in this paper are translated into recommendations for a more efficient grey-box model identification process for landscaped offices conditioned by an air-based system. These guidelines should lead to an improved applicability of MPC for allair systems. This paper is based on the first author's Master's thesis [6].

\section{Case study building}

\subsection{Building and systems}

The case study building is an office building from 2012 situated in Heverlee (Belgium) and has a building envelope with an average U-value of $0.38 \mathrm{~W} / \mathrm{m}^{2} \mathrm{~K}$ [7]. The office building contains four floors, of which two office floors, each floor is approximately $1280 \mathrm{~m}^{2}$, with two landscaped offices each. Every landscaped office is divided into three office zones as indicated on Figure 1. These zones are not physically separated from each

\footnotetext{
${ }^{*}$ Corresponding author: quinten.carton@,kuleuven.be
} 
other, which makes influence from neighbouring zones possible. The control of the heating and ventilation happens independently for each office zone. The office zones are not actively cooled.

The building uses an all-air HVAC system consisting of an air-handling unit (AHU) where the air is pre-heated two times, i.e., by the thermal wheel and central heating coil. Afterwards, the air is transported from the AHU to a circuit conduct in each floor. The inlet air is then transferred through branches to the office zones with inlet openings in the ceiling. The inlet air flow to an office zone is controlled by a variable air volume (VAV) unit, while the inlet air temperature is adjusted by a decentral heating coil.

The setpoints, e.g., zone temperature setpoint of $24.3^{\circ} \mathrm{C}, \mathrm{CO}_{2}$ setpoint of $800 \mathrm{ppm}$, and clock control, operational from 6 am till $6 \mathrm{pm}$, for the HVAC system are adjustable through the building management system (BMS). Furthermore, the BMS saves measurements from different sensors every 15 minutes.

\subsection{Office zone}

This paper analyses the prediction accuracies of different grey-box models for a zone of the landscaped office in the case study building. The tested zone B is located on the top floor of the building and is enclosed by two neighbouring zones $\mathrm{A}$ and $\mathrm{C}$ (see Figure 1).

Table 1 gives the properties of the tested office zone.

Table 1. Properties of the tested office zone B

\begin{tabular}{|l|l|}
\hline Floor area & $70 \mathrm{~m}^{2}$ \\
\hline Volume & $224 \mathrm{~m}^{3}$ \\
\hline Design occupancy & $12 \mathrm{pers}$ or $5.8 \mathrm{~m}^{2} /$ pers \\
\hline $\begin{array}{l}\text { Minimal ventilation } \\
\text { flow rate }\end{array}$ & $63 \mathrm{~m}^{3} / \mathrm{h}$ \\
\hline $\begin{array}{l}\text { Maximal ventilation } \\
\text { flow rate }\end{array}$ & $420 \mathrm{~m}^{3} / \mathrm{h}$ or $35 \mathrm{~m}^{3} / \mathrm{h} . \mathrm{pers}$ \\
\hline $\begin{array}{l}\text { Maximum power } \\
\text { decentral heating coil }\end{array}$ & $1900 \mathrm{~W}$ \\
\hline $\begin{array}{l}\text { Window to wall ratio } \\
\text { (WWR) }\end{array}$ & 0.29 \\
\hline Orientation & North east $(\mathrm{NE})$ \\
\hline
\end{tabular}

\section{Method}

\subsection{Data acquisition and datasets}

The building is monitored during two different periods, i.e., summer (July-August) and winter (NovemberJanuary) conditions. The data used for the identification and validation of the grey-box models is acquired from three sources. The first source is the BMS which saves measurement data from the sensors spread across the office building. The zone temperature, $\mathrm{CO}_{2}$ concentration and air flow rate are used for constructing the datasets. The BMS measures the different states with a time step of 15 minutes. The second source is a database with measurements coming from a network of weather stations (Renkforce WH2600) near the case study building [8]. The distance between the building

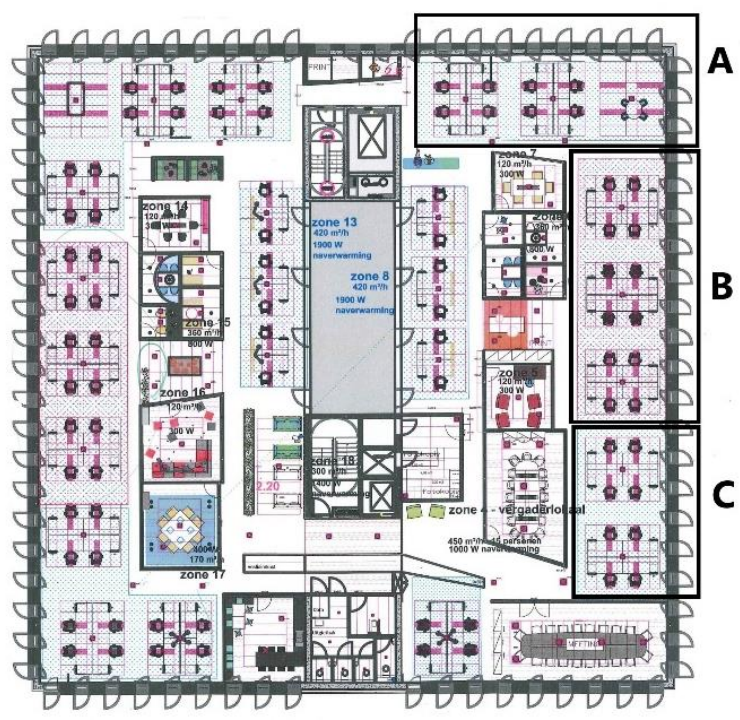

Figure 1. Floor plan with neighbouring zone A, tested zone $\mathrm{B}$ and neighbouring zone $\mathrm{C}$

and the weather station is $1,1 \mathrm{~km}$. A time step of 16 seconds is used in the database. Therefore, a resampling of the data into a time step of 15 minutes is necessary. The properties of the sensors used in the office building and weather station are given in Table 2. Finally, the occupancy in the office zones is determined through a survey of the employees. This survey involves the employees keeping track of their attendance per hour for one week. In addition, occupants are asked to what extend their presence in the monitored week deviates from an average week. A reference week of the actual occupancy per hour and per zone is determined. During the summer, the occupancy profiles are modified to deal with the absence of persons on holidays: the occupancy during July and August is assumed to be half of the occupancy during the other months.

Table 2. Properties of the sensors

\begin{tabular}{|l|l|}
\hline Parameter & Accuracy \\
\hline Indoor temperature (BMS) & $\pm 0.15^{\circ} \mathrm{C}$ \\
\hline $\mathrm{CO}_{2}$-concentration (BMS) & $\pm 30 \mathrm{ppm}+$ \\
& $2 \%$ reading \\
\hline Outside temperature (weather station) & $\pm 1{ }^{\circ} \mathrm{C}$ \\
\hline Solar irradiation (weather station) & $\pm 15 \%$ \\
\hline
\end{tabular}

A total of eight datasets are constructed. Datasets 14 have a dataset size of 5 days corresponding with one working week. While datasets 5-8 consist of 12 days of measurements which is equivalent to two working weeks with the enclosed weekend. Table 3 shows the datasets with the matching measurement period and weather and occupancy characteristics.

\subsection{Model identification}

Since the case study building is equipped with an all-air HVAC system, a MPC should predict both the indoor temperature and the $\mathrm{CO}_{2}$-levels. Therefore, two model types are identified in this paper, i.e., temperature models for predicting the zone temperature and $\mathrm{CO}_{2}$ models for predicting the zone $\mathrm{CO}_{2}$-concentration. For 
each model type, eight predictive models are identified, evaluated and validated using the continuous time stochastic modelling (CTSM) toolbox for R [9]. An input dataset consisting of winter data is used for the model identification and evaluation. Hereafter, the identified models are validated using both winter and summer data shown in Table 3. The identification, evaluation and validation process of the sixteen models is done for both the 5-day and 12-day datasets.

Table 3 Properties datasets

\begin{tabular}{|c|c|c|c|}
\hline$n^{\circ}$ & Period & Size & Characteristics \\
\hline 1 & $\begin{array}{c}25 / 11 / 2019- \\
29 / 11 / 2019 \\
\end{array}$ & \multirow{3}{*}{$\begin{array}{c}5 \\
\text { days }\end{array}$} & \multirow{6}{*}{$\begin{array}{c}\text { Low outside } \\
\text { temperatures } \\
\text { Low solar irradiation } \\
\text { Normal occupancy }\end{array}$} \\
\hline 2 & $\begin{array}{c}02 / 12 / 2019- \\
06 / 12 / 2019 \\
\end{array}$ & & \\
\hline 3 & $\begin{array}{c}27 / 01 / 2020- \\
31 / 01 / 2020\end{array}$ & & \\
\hline 5 & $\begin{array}{c}25 / 11 / 2019- \\
06 / 12 / 2019\end{array}$ & \multirow{3}{*}{$\begin{array}{c}12 \\
\text { days }\end{array}$} & \\
\hline 6 & $\begin{array}{c}09 / 12 / 2019- \\
20 / 12 / 2019\end{array}$ & & \\
\hline 7 & $\begin{array}{c}20 / 01 / 2020- \\
31 / 01 / 2020\end{array}$ & & \\
\hline 4 & $\begin{array}{c}01 / 07 / 2019- \\
05 / 07 / 2019\end{array}$ & $\begin{array}{c}5 \\
\text { days }\end{array}$ & \multirow{2}{*}{$\begin{array}{c}\text { High outside } \\
\text { temperatures } \\
\text { High solar irradiation } \\
\text { Low occupancy }\end{array}$} \\
\hline 8 & $\begin{array}{c}29 / 07 / 2019- \\
09 / 08 / 2019\end{array}$ & $\begin{array}{c}12 \\
\text { days }\end{array}$ & \\
\hline
\end{tabular}

\subsection{Model evaluation and validation}

The model evaluation and validation process is based on the guidelines, specified within IEA EBC Annex 58 by Madsen et al. [4].

The model evaluation starts with a parameter control for each identified model determining the parameters significance and correlation. The parameter significance is evaluated by a t-test. A parameter is insignificant when the p-value exceeds 0,05 . Two parameters are too closely linked when the correlation factor is above $|0,98|$. Afterwards, the preferable model complexity is determined by a likelihood ratio test between the different models based on their input dataset.

The results are then further analysed through the model validation process. For instance, the root mean square error (RMSE) and maximum errors achieved by the models for validation datasets are calculated. This evaluates the prediction accuracy of the models. The errors are calculated for multiple prediction steps, i.e., $15 \mathrm{~min}, 30 \mathrm{~min}, 45 \mathrm{~min}, 1 \mathrm{~h}, 2 \mathrm{~h}, 4 \mathrm{~h}, 12 \mathrm{~h}$ and 1 day to determine the acceptable prediction horizon.

Three different validation datasets measured during different periods, thus during different conditions, are used for the validation of the grey-box models. The validation datasets have different degrees of discrepancies from the input dataset, with the summer data (datasets 4 and 8 ) as the most deviating scenario. The suitability of the models in different conditions is determined by checking if the residuals are white noise or due to an inaccurate model, which is tested by the auto-correlation function (ACF) and the cumulated periodogram (CP). The test for white noise succeeds, meaning the residuals are white noise, if in the ACF not more than $5 \%-10 \%$ of the lag correlations exceed the 95\% confidence bound and no exponential decaying pattern from lag one can be determine and no cyclic behaviour is visible in the CP [4]. Hereafter, the residuals are plotted and analysed in detail.

\section{Results and discussion}

\subsection{Temperature models}

\subsubsection{Identified models}

Table 4 shows the properties of the developed temperature models and the used input dataset (see Table 3).

Table 4. Temperature models

\begin{tabular}{|c|c|c|c|}
\hline \multirow{2}{*}{$\begin{array}{l}\text { Model } \\
\text { name }\end{array}$} & \multirow{2}{*}{$\begin{array}{l}\text { Included } \\
\text { parameters }\end{array}$} & \multicolumn{2}{|c|}{ Input dataset $\left(n^{\circ}\right)$} \\
\hline & & 5 days & 12 days \\
\hline Model 1 & Base model & 1 & 5 \\
\hline Model 2 & $+\mathrm{P}_{\mathrm{B}}$ & 1 & 5 \\
\hline Model 3 & $+\mathrm{T}_{\mathrm{A}}$ & 1 & 5 \\
\hline Model 3a & $+T_{A}-P_{B}$ & 1 & 6 \\
\hline Model 4 & $+\mathrm{T}_{\mathrm{C}}$ & 1 & 5 \\
\hline Model 4a & $+\mathrm{T}_{\mathrm{C}}-\mathrm{P}_{\mathrm{B}}$ & 1 & 5 \\
\hline Model 5 & $+\mathrm{T}_{\mathrm{A}}-\mathrm{T}_{\mathrm{C}}$ & 2 & 7 \\
\hline Model 5a & $+T_{A}-T_{C}-P_{B}$ & 1 & 5 \\
\hline
\end{tabular}

The dynamic heat transfer in the office zone is represented by a resistance-capacity (RC) model. The temperature models consist of differential equations of which the number corresponds to the amount of temperature states. The base temperature model (model 1 in Table 4) is a two state RC model with the indoor temperature $\left(\mathrm{T}_{\mathrm{B}}\right)$ of zone $\mathrm{B}$ and the external temperature $\left(T_{e}\right)$ as the two temperature states. The base $2^{\text {nd }}$ order model is made more complex up to a $4^{\text {th }}$ order model by adding the number of occupants $\left(\mathrm{P}_{\mathrm{B}}\right)$ and the temperature states of neighbouring zones $\left(\mathrm{T}_{\mathrm{A}}, \mathrm{T}_{\mathrm{C}}\right)$. Equation 1 is the differential equation for the indoor temperature of the most complex temperature model (model 5a in Table 4).

$$
\begin{gathered}
d T_{B}=\left\{\left[1 /\left(C_{B} * R_{B e}\right) *\left(T_{e}-T_{B}\right)\right]+\left[1 /\left(C_{B} * R_{A B}\right) *\left(T_{A}-T_{B}\right)\right]+\right. \\
{\left[1 /\left(C_{B} * R_{C B}\right) *\left(T_{C}-T_{B}\right)\right]+\left[\left(g A * P_{S}\right) / C_{B}\right]+\left(P_{h} / C_{B}\right)+} \\
\left.\left[\left(P_{B} * 0,070\right) / C_{B}\right]\right\} d t+\sigma i * d \omega i
\end{gathered}
$$

$\mathrm{T}_{\mathrm{B}}$ : Indoor temperature tested zone $\mathrm{B}\left[{ }^{\circ} \mathrm{C}\right]$

$\mathrm{T}_{\mathrm{e}}$ : External temperature $\left[{ }^{\circ} \mathrm{C}\right]$

$\mathrm{T}_{\mathrm{A}}$ : Indoor temperature neighbouring zone $\mathrm{A}\left[{ }^{\circ} \mathrm{C}\right]$

$\mathrm{T}_{\mathrm{C}}$ : Indoor temperature neighbouring zone $\mathrm{C}\left[{ }^{\circ} \mathrm{C}\right]$

$\mathrm{R}_{\mathrm{Be}}$ : Thermal resistance inner shell façade $\left[{ }^{\circ} \mathrm{C} / \mathrm{kW}\right]$

$\mathrm{R}_{\mathrm{AB}}$ : Thermal resistance separation between tested zone $\mathrm{B}$ and neighbouring zone $\mathrm{A}\left[{ }^{\circ} \mathrm{C} / \mathrm{kW}\right]$

$\mathrm{R}_{\mathrm{CB}}$ : Thermal resistance separation between tested zone $\mathrm{B}$ and neighbouring zone $\mathrm{C}\left[{ }^{\circ} \mathrm{C} / \mathrm{kW}\right]$ $\mathrm{C}_{\mathrm{B}}$ : Thermal capacity tested zone $\mathrm{B}\left[\mathrm{kJ} /{ }^{\circ} \mathrm{C}\right]$ 
gA: Product of total solar energy transmittance $(\mathrm{g})$ and effective area of the windows (A) $\left[\mathrm{m}^{2}\right]$

$\mathrm{P}_{\mathrm{s}}$ : Solar irradiation $\left[\mathrm{kW} / \mathrm{m}^{2}\right]$

$\mathrm{P}_{\mathrm{h}}$ : Heating power of the heating coils [kW]

$\mathrm{P}_{\mathrm{B}}$ : Occupancy in tested zone B [-]

$\sigma_{i}$ : Variance of the Wiener process [-]

$\mathrm{d} \omega_{\mathrm{i}}$ : Wiener process [-]

\subsubsection{Parameter convergence and significance}

The first step is to evaluate the models by analysing the parameters convergence and significance. A difference is noticeable between the temperature models identified on 5- and 12-day datasets (see Table 4). With the 5-day datasets it is possible to gain a parameter convergence using dataset 1 for all models except model 5, where dataset 2 needs to be used. The parameter convergence is harder to achieve when using 12-day datasets. Two models (model 3a and model 5) cannot become a parameter convergence using dataset 5 . Model 5 cannot even obtain a parameter convergence for dataset 6 , therefore dataset 7 has to be used for the identification of this temperature model. This demonstrates that a larger dataset size for this case results in a harder parameter convergence.

The parameter control of the temperature models shows that all models, except model 5a, have one or more insignificant parameters for both dataset sizes. The parameter $\mathrm{gA}$ is considered insignificant in the majority of the models. This means that the solar heat transfer is neglected in the majority of the models. This can be due to the NE orientation of the tested zone making it difficult to estimate the gA-value. Furthermore, the global horizontal irradiance from the weather station is used, while the vertical solar irradiance measured at the building façade would be more accurate, but this data lacked.

Another observation is that the models identified with 12-day datasets have few or none insignificant thermal capacities compared with models using 5-day datasets. This makes models using 12-day datasets more capable of predicting the thermal inertia of the building. This can be caused by the enclosed weekend that is measured in the 12-day dataset. During the weekend the building is not conditioned or occupied which makes it easier to determine the buildings thermal properties.

\subsubsection{Model complexity}

The likelihood ratio test determines which model complexity is preferred. Based on the likelihood ratio test model 3 and 4 are the preferred temperature models identified with a 5- and, 12-day dataset respectively, thus showing a different result for both dataset sizes. Furthermore, the temperature models with an occupant parameter (model 2 and a-models) are not preferred above the models without such an occupant parameter. This indicates that the internal heat gains from occupants are distributed over other parameters in the models that lack an occupant parameter, which could lead to a less accurate estimation of the thermal inertia of the building. The next paragraph investigates if the same conclusions can be made based on the model accuracy.

\subsubsection{Model accuracy}

Similar observations as in 4.1 .3 can be obtained from Table 5 and Table 6, showing the RMSE and maximum errors from each model using a 5- and 12-day winter validation dataset respectively. A first observation valid for both dataset sizes is that the models with an occupant parameter (a-models) show higher prediction errors than models without this parameter, which is probably caused by the inaccurate occupancy measurement method. Models 3a and 5a using 12-day data are exceptions as other input datasets have been used to identify models $3 \mathrm{a}$ and 5 . Furthermore, it appears that the two-state models (Model 1 and 2) have a significant lower prediction accuracy than the three-state models (model 3 and 4 ) in both situations. In addition, the $4^{\text {th }}$ order model 5 obtains lower prediction errors than the $3^{\text {rd }}$ order models 3 and 4 in the 5 -day situation. This is mostly due to the fact that the validation dataset used for model 5 has a steadier course than the dataset used for models 3 and 4, which makes temperature predictions easier. The four-state model 5 shows higher maximum errors in the 12-day situation, due to the fact that model 5 is validated with a more varying dataset. Model 5 is excluded from the comparison since it is validated using another dataset than the other models.

The most preferable model in the 5-day scenario is model 3 , since this model obtains the lowest maximum errors of all models except model 5. The RMSE obtained by model 3 is higher than with model 4 for high prediction steps, but the deviation is neglectable.

Table 5. Prediction errors for temperature models using 5day datasets. The relative low and high prediction errors are coloured in green and red respectively.

\begin{tabular}{|c|c|c|c|c|c|c|c|c|}
\hline & \multicolumn{8}{|c|}{$\mathrm{RMSE}\left[{ }^{\circ} \mathrm{C}\right]$} \\
\hline 总 & $\begin{array}{l}7 \\
\frac{0}{0} \\
\sum\end{array}$ & $\frac{N}{\frac{N}{0}}$ & $\frac{\frac{m}{0}}{\frac{0}{0}}$ & $\frac{\pi}{\frac{\pi}{0}}$ & $\begin{array}{l}\frac{\nabla}{0} \\
\frac{0}{0} \\
\dot{0}\end{array}$ & $\frac{\frac{\pi}{+}}{\frac{0}{8}}$ & $\begin{array}{l}\frac{n}{0} \\
\frac{0}{0} \\
\sum\end{array}$ & $\frac{\pi}{\frac{\pi}{n}}$ \\
\hline $15 \mathrm{~min}$ & 0.11 & 0.12 & 0.11 & 0.12 & 0.11 & 0.12 & 0.09 & 0.11 \\
\hline $30 \mathrm{~min}$ & 0.15 & 0.17 & 0.15 & 0.16 & 0.15 & 0.16 & 0.11 & 0.15 \\
\hline $45 \mathrm{~min}$ & 0.17 & 0.20 & 0.17 & 0.19 & 0.16 & 0.18 & 0.13 & 0.17 \\
\hline $1 \mathrm{~h}$ & 0.18 & 0.22 & 0.18 & 0.20 & 0.17 & 0.20 & 0.13 & 0.17 \\
\hline $2 \mathrm{~h}$ & 0.19 & 0.24 & 0.19 & 0.22 & 0.18 & 0.22 & 0.15 & 0.19 \\
\hline $4 \mathrm{~h}$ & 0.21 & 0.26 & 0.19 & 0.23 & 0.18 & 0.23 & 0.17 & 0.19 \\
\hline $12 \mathrm{~h}$ & 0.26 & 0.31 & 0.20 & 0.25 & 0.18 & 0.26 & 0.19 & 0.22 \\
\hline \multirow[t]{2}{*}{1 day } & 0.29 & 0.38 & 0.22 & 0.29 & 0.18 & 0.30 & 0.16 & 0.25 \\
\hline & \multicolumn{8}{|c|}{ Maximum error $\left[{ }^{\circ} \mathrm{C}\right]$} \\
\hline $15 \mathrm{~min}$ & 0.73 & 0.73 & 0.74 & 0.68 & 0.70 & 0.70 & 0.48 & 0.68 \\
\hline $30 \mathrm{~min}$ & 0.91 & 0.87 & 0.77 & 0.78 & 0.74 & 0.81 & 0.60 & 0.77 \\
\hline $45 \mathrm{~min}$ & 0.94 & 0.88 & 0.73 & \begin{tabular}{|l}
0.76 \\
\end{tabular} & 0.74 & 0.81 & 0.61 & 0.74 \\
\hline $1 \mathrm{~h}$ & 1.00 & 0.90 & 0.71 & 0.77 & 0.76 & 0.84 & 0.60 & 0.76 \\
\hline $2 \mathrm{~h}$ & 0.88 & 0.87 & 0.66 & 0.79 & 0.80 & 0.73 & 0.61 & 0.77 \\
\hline $4 \mathrm{~h}$ & 0.85 & 0.89 & 0.68 & 0.81 & 0.82 & 0.76 & 0.74 & 0.80 \\
\hline $12 \mathrm{~h}$ & 0.91 & 0.90 & 0.70 & 0.82 & 0.82 & 0.82 & 0.70 & 0.81 \\
\hline 1 day & 0.91 & 0.95 & 0.72 & 0.82 & 0.81 & 0.84 & 0.70 & 0.82 \\
\hline
\end{tabular}


Table 6. Prediction errors for temperature models using 12day datasets. The relative low and high prediction errors are coloured in green and red respectively.

\begin{tabular}{|c|c|c|c|c|c|c|c|c|}
\hline & \multicolumn{8}{|c|}{$\mathrm{RMSE}\left[{ }^{\circ} \mathrm{C}\right]$} \\
\hline 兽 & $\begin{array}{l}\bar{\Xi} \\
\frac{0}{8} \\
\dot{0}\end{array}$ & $\frac{N}{\frac{N}{0}}$ & $\frac{\frac{m}{0}}{\frac{0}{\delta}}$ & $\begin{array}{l}\pi \\
\tilde{D} \\
\frac{0}{0} \\
\sum\end{array}$ & $\begin{array}{l}\dot{J} \\
\frac{0}{0} \\
\dot{0}\end{array}$ & $\frac{\frac{\pi}{+}}{\frac{0}{8}}$ & $\frac{n}{\frac{0}{8}}$ & $\frac{\pi}{n}$ \\
\hline $15 \mathrm{~min}$ & 0.13 & 0.10 & 0.10 & 0.09 & 0.10 & 0.10 & 0.10 & 0.10 \\
\hline $30 \mathrm{~min}$ & 0.20 & 0.14 & 0.14 & 0.13 & 0.13 & 0.14 & 0.13 & 0.13 \\
\hline $45 \mathrm{~min}$ & 0.25 & 0.16 & 0.16 & 0.14 & 0.15 & 0.16 & 0.14 & 0.14 \\
\hline $1 \mathrm{~h}$ & 0.30 & 0.17 & 0.17 & 0.15 & 0.16 & 0.17 & 0.14 & 0.14 \\
\hline $2 \mathrm{~h}$ & 0.45 & 0.20 & 0.19 & 0.15 & 0.19 & 0.21 & 0.15 & 0.16 \\
\hline $4 \mathrm{~h}$ & 0.69 & 0.23 & 0.20 & 0.16 & 0.21 & 0.24 & 0.15 & 0.17 \\
\hline $12 \mathrm{~h}$ & 1.25 & 0.31 & 0.21 & 0.18 & 0.23 & 0.28 & 0.16 & 0.19 \\
\hline \multirow[t]{2}{*}{1 day } & 0.97 & 0.41 & 0.22 & 0.19 & 0.25 & 0.31 & 0.16 & 0.21 \\
\hline & \multicolumn{8}{|c|}{ Maximum error $\left[{ }^{\circ} \mathrm{C}\right]$} \\
\hline $15 \mathrm{~min}$ & 0.88 & 0.78 & 0.79 & 0.70 & 0.80 & 0.81 & 0.74 & 0.80 \\
\hline $30 \mathrm{~min}$ & 1.47 & 0.82 & 0.79 & 0.82 & 0.80 & 0.87 & 0.89 & 0.80 \\
\hline $45 \mathrm{~min}$ & 1.94 & 0.97 & 0.80 & 0.83 & 0.86 & 1.04 & 0.91 & 0.83 \\
\hline $1 \mathrm{~h}$ & 2.10 & 0.99 & 0.78 & 0.82 & 0.87 & 1.07 & 0.90 & 0.80 \\
\hline $2 \mathrm{~h}$ & 2.42 & 0.87 & 0.78 & 0.85 & 0.84 & 0.95 & 0.95 & 0.82 \\
\hline $4 \mathrm{~h}$ & 2.43 & 0.93 & 0.80 & 0.90 & 0.85 & 0.91 & 1.02 & 0.85 \\
\hline $12 \mathrm{~h}$ & 3.06 & 1.11 & 0.89 & 1.05 & 0.84 & 0.95 & 1.15 & 0.81 \\
\hline 1 day & 2.28 & 1.11 & 0.97 & 1.09 & 0.81 & 0.95 & 1.14 & 0.86 \\
\hline
\end{tabular}

Models 4 and 5a are the most accurate temperature models using 12-day datasets. The RMSE obtained with model $5 \mathrm{a}$ is lower than obtained with model 4 . The deviation between the maximum errors obtained with both models is maximum $0.07^{\circ} \mathrm{C}$, which is below the sensor accuracy of $0.15^{\circ} \mathrm{C}$. In this case the least complex model 4 is preferred over model $5 \mathrm{a}$.

It has been found that the most accurate model differs in the 5- and 12-day situation. There are no significant differences between the RMSE obtained with model 3 (5day) and 4 (12day). On the other hand, the deviation between the maximum errors runs up to $0.18^{\circ} \mathrm{C}$, which exceeds the temperature sensor accuracy. Therefore, model 3 using 5-day datasets is favoured above model 4 using 12-day datasets. Furthermore, the use of 5-day datasets is preferred over 12-day datasets since it requires a shorter monitoring period.

\subsubsection{Impact changing conditions}

The usability of the most accurate model, i.e., model 3 with a 5-day dataset, in different conditions is determined by comparing the ACF, $\mathrm{CP}$ and the residuals course on winter and summer validation data. Figure 2 shows the ACF and the $\mathrm{CP}$ in the case of winter and summer conditions. It is visible that the residuals stay within the $95 \%$ confidence boundaries for the winter data, which means the residuals can be classified as white noise. On the contrary, the test on white noise fails when using summer data. The residual course using winter data is analysed using Figure 3. The residuals course during the winter shows two types of peaks. The first type of peaks happens two times a day and matches the on and off switches of the heating system, meaning these peaks are due to the clock control of the HVACsystem. The second type of peaks are due to inaccurate measurements, visible through the sudden drops in zone temperature and heat supply. The residuals of model 3 when using summer validation data show a more fluctuating course, which could be due to the insignificance of the parameter $\mathrm{gA}$ in model 3 (see 4.1.2). The temperature models in this paper neglect the solar heat gains through the windows, while the solar radiation reaches significant values during sunny days, leading to inaccurate predictions.
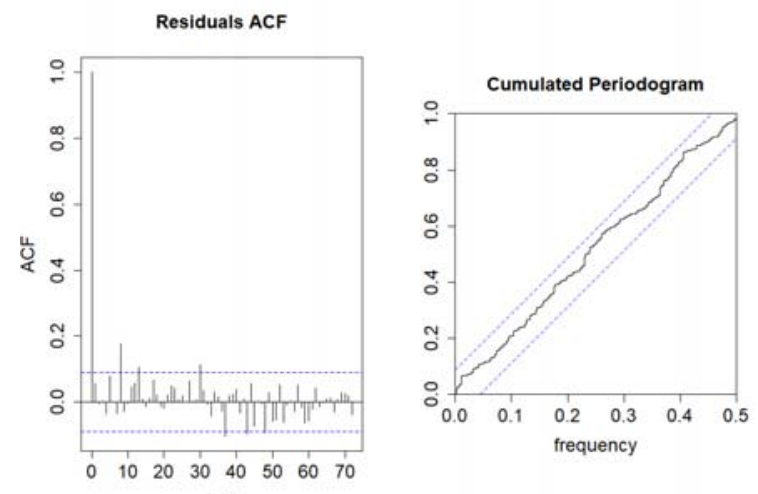

Lag
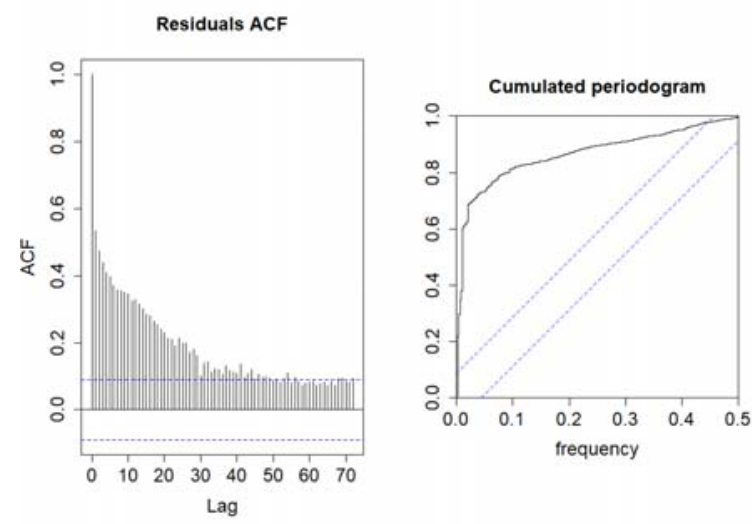

Figure 2. ACF and CP for model 3 validated with winter (above) and summer (below) data

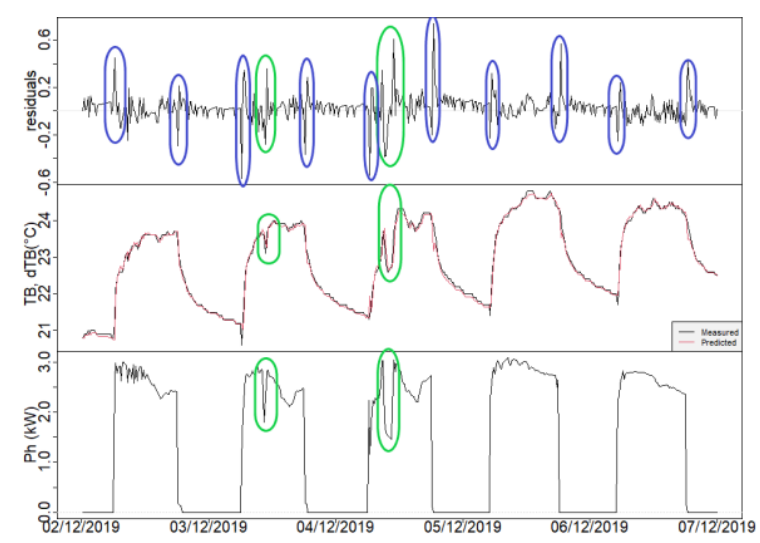

Figure 3. Plot of the residuals for a one step ahead prediction (15 min) of model 3 marking the clock control (blue) and inaccurate measurements (green) using winter validation data

\subsubsection{Prediction horizon}

The prediction errors per prediction step, e.g. one step ahead $=15 \mathrm{~min}$, two steps ahead $=30 \mathrm{~min}$, etc., for model 3 are given in Table 5. The table shows that the discrepancies between the maximum errors do not 
exceed the sensor accuracy of $0.15^{\circ} \mathrm{C}$. Nevertheless, it is false to state that no practical differences are noticeable between the absolute prediction errors for the different prediction steps. As shown in Figure 3, the maximum errors are due to the clock control of the HVAC system or inaccurate measurements. A further model optimisation will not eliminate this type of prediction error. Therefore, the difference between the absolute errors, excluding the ones caused by the clock control, are determined based on the RMSE. The RMSE at a prediction step of 1 day is twice the RMSE at 15 minutes. Figure 3 shows the residuals for model 3 using a one step ahead prediction of 15 minutes. The prediction errors that are not caused by the clock control or inaccurate measurements vary between $0.1^{\circ} \mathrm{C}$ and $0.2^{\circ} \mathrm{C}$. A doubling of the RMSE at a 1-day prediction step means the absolute errors vary between $0.2^{\circ} \mathrm{C}$ and $0.4^{\circ} \mathrm{C}$.

A prediction horizon of 15 minutes is acceptable if a prediction accuracy lower than the sensor accuracy $\left(0.15^{\circ} \mathrm{C}\right)$ is pursued. The absolute prediction errors in other research [5], [10] range from $0.30^{\circ} \mathrm{C}-1^{\circ} \mathrm{C}$. Therefore, a prediction horizon of 1 day, obtaining a maximum error of $0.4^{\circ} \mathrm{C}$, is acceptable considering the higher prediction errors in comparable literature.

\section{$4.2 \mathrm{CO}_{2}$-models}

\subsubsection{Identified models}

Table 7 shows the properties of the $\mathrm{CO}_{2}$-models.

Table 7. $\mathrm{CO}_{2}$-models

\begin{tabular}{|l|c|}
\hline Model name & Included parameters \\
\hline Model 6 & Base model \\
\hline Model 7 & $+\mathrm{Q}_{\text {inf }}$ \\
\hline Model 8 & $+\mathrm{P}_{\mathrm{A}}$ \\
\hline Model $8 \mathrm{a}$ & $+\mathrm{P}_{\mathrm{A}}-\mathrm{Q}_{\text {inf }}$ \\
\hline Model 9 & $+\mathrm{P}_{\mathrm{C}}$ \\
\hline Model $9 \mathrm{a}$ & $+\mathrm{P}_{\mathrm{C}}-\mathrm{Q}_{\text {inf }}$ \\
\hline Model 10 & $+\mathrm{P}_{\mathrm{A}}-\mathrm{P}_{\mathrm{C}}$ \\
\hline Model 10a & $+\mathrm{P}_{\mathrm{A}}-\mathrm{P}_{\mathrm{C}}-\mathrm{Q}_{\text {inf }}$ \\
\hline
\end{tabular}

All $\mathrm{CO}_{2}$-models are one state grey-box models with a differential equation representing the mass balance of the $\mathrm{CO}_{2}$-concentration in the tested zone. The $\mathrm{CO}_{2}$ concentration of the outdoor air is assumed to be fixed at $470 \mathrm{ppm}$, i.e., the average outdoor $\mathrm{CO}_{2}$-level over the period 25/11/2019 - 20/12/2019. The base model 6 is modified by adding the infiltration rate $\left(\mathrm{Q}_{\text {inf }}\right)$ and the occupancy of one or two adjacent zones $\left(\mathrm{P}_{\mathrm{A}}, \mathrm{P}_{\mathrm{C}}\right)$. The occupancy of the adjacent zones is divided by a reduction factor $\left(\mathrm{n}_{\mathrm{A}}, \mathrm{n}_{\mathrm{C}}\right)$. The reduction factor is estimated and its value can range from one to two. The implementation of the occupancy of the neighbouring zones is a method to determine the influence of the adjacent zones on the $\mathrm{CO}_{2}$-concentration of the testing zone. Using the $\mathrm{CO}_{2}$-concentration of the neighbouring zones would be more accurate, but this data was missing in the case study building. Equation 2 is the differential equation of the indoor $\mathrm{CO}_{2}$-concentration for the most complex $\mathrm{CO}_{2}$-model, i.e., model 10a in Table 7.

$$
\begin{gathered}
d C_{B}=\left\{\left[(A F / 3600) *\left(470-C_{B}\right)+\left(P_{B}+P_{A} / n_{A}+P_{C} / n_{C}\right) * G_{o c c}+\right.\right. \\
\left.\left.Q_{i n f} *\left(470-C_{B}\right)\right] / 224\right\} d t+\sigma i * d \omega i
\end{gathered}
$$

$\mathrm{C}_{\mathrm{B}}: \mathrm{CO}_{2}$-concentration in tested zone $\mathrm{B}$ [ppm]

AF: Ventilation flow rate $\left[\mathrm{m}^{3} / \mathrm{h}\right]$

$\mathrm{P}_{\mathrm{B}}$ : Occupancy in tested zone $\mathrm{B}[-]$

$\mathrm{P}_{\mathrm{A}}$ : Occupancy in neighbouring zone A [-]

$\mathrm{P}_{\mathrm{C}}$ : Occupancy in neighbouring zone $\mathrm{C}[-]$

$\mathrm{n}_{\mathrm{A}}$ : Reduction factor neighbouring zone A [-]

$\mathrm{n}_{\mathrm{c}}$ : Reduction factor neighbouring zone $\mathrm{C}[-]$

$\mathrm{G}_{\mathrm{occ}}$ : $\mathrm{CO}_{2}$-production per person [mg/s]

Qinf: Infiltration flow rate $\left[\mathrm{m}^{3} / \mathrm{s}\right]$

$\sigma_{\mathrm{i}}$ : Variance of the Wiener process [-]

$\mathrm{d} \omega_{\mathrm{i}}$ : Wiener process [-]

\subsubsection{Parameter convergence and significance}

All $\mathrm{CO}_{2}$-models obtain a parameter convergence during the model identification for both dataset sizes without the need to change the input dataset.

All parameters are significant in all models and for all dataset sizes, except for the reduction parameter $n_{A}$ in model 9 for a 5-day dataset. The parameter $n_{A}$ is not of great importance, thus its insignificance can be neglected. Furthermore, there are no correlations noticed between the parameters.

\subsubsection{Model complexity}

The likelihood ratio test shows a similar result for both the 5- and 12-day scenario. In both cases, it appears that the models with an infiltration rate parameter are preferred above the ones without. The most complex model (model 10a) is the preferred model for both dataset sizes based on the likelihood ratio test.

\subsubsection{Model accuracy}

The prediction accuracies achieved by the $\mathrm{CO}_{2}$-models for the summer validation datasets nuance the results of the likelihood ration test. Table 8 and Table 9 show the RMSE and maximum error obtained with each model with respectively the 5- and 12-day dataset. The deviations between the errors of the different models only exceed the sensor accuracy of $70 \mathrm{ppm}$ a few times for large prediction steps of $12 \mathrm{~h}$ and 1day. Both tables show lower errors for the models with the parameter $Q_{\text {inf }}$ (model 7 and a-models) at prediction steps of $2 \mathrm{~h}$ and higher, but the maximum errors still exceed the sensor accuracy of $70 \mathrm{ppm}$. In practice, the prediction horizon is usually limited to $2 \mathrm{~h}$, due to the fast-changing characteristics of the $\mathrm{CO}_{2}$-concentration in a room. Therefore, the use of parameter $\mathrm{Q}_{\mathrm{inf}}$ is not categorised as an improvement for the prediction accuracy of $\mathrm{CO}_{2}$ models. The implementation of the occupancy in neighbouring zones show little to no improvement in the models' prediction accuracy. Therefore, the least complex model is preferred, in this case model 6 .

The discrepancies between the RMSEs obtained with model 6 using 5- and 12-day data respectively are neglectable. The maximum errors of model 6 using 5day data are lower for all prediction steps compared to using 12-day data. The deviation runs up to $122 \mathrm{ppm}$ 
which exceeds the sensor accuracy of $70 \mathrm{ppm}$. It should be noted that the deviation between the maximum errors do not exceed the sensor accuracy for prediction steps lower than $4 \mathrm{~h}$. This means that the difference in prediction accuracy is not noticeable in practice. Nonetheless, a 5-day dataset is preferred due to its shorter monitoring period resulting in a faster model identification process.

Table 8. Prediction errors for $\mathrm{CO}_{2}$-models using 5-day datasets. The relative low and high prediction errors are coloured in green and red respectively.

\begin{tabular}{|c|c|c|c|c|c|c|c|c|}
\hline & \multicolumn{8}{|c|}{ RMSE [ppm] } \\
\hline 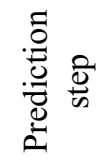 & $\begin{array}{l}0 \\
\frac{0}{0} \\
\dot{0}\end{array}$ & $\frac{\overline{0}}{\frac{0}{0}}$ & $\frac{\infty}{\frac{0}{0}}$ & $\begin{array}{l}\frac{\pi}{\infty} \\
\frac{0}{0} \\
\frac{0}{2}\end{array}$ & $\frac{\frac{a}{0}}{\frac{0}{0}}$ & $\frac{\frac{\pi}{0}}{\frac{0}{0}}$ & $\begin{array}{l}0 \\
0 \\
\frac{0}{0} \\
\dot{0}\end{array}$ & $\frac{\pi}{0}$ \\
\hline & & & & 4 & 15 & 14 & 15 & 14 \\
\hline $30 \mathrm{~m}$ & 20 & 19 & 20 & 19 & 20 & 19 & 20 & 19 \\
\hline $45 \mathrm{~m}$ & & & 24 & 23 & 24 & 23 & & 24 \\
\hline $1 \mathrm{~h}$ & 27 & 27 & 28 & 26 & 27 & 26 & 21 & 27 \\
\hline $2 \mathrm{~h}$ & & & 40 & 37 & 40 & 37 & 0 & 38 \\
\hline $4 \mathrm{~h}$ & 56 & 52 & 59 & 51 & 59 & 51 & 59 & 55 \\
\hline $12 \mathrm{~h}$ & & 60 & 95 & 63 & 92 & 63 & 95 & 72 \\
\hline 1 day & & 46 & 111 & 45 & 106 & 49 & 111 & 45 \\
\hline & \multicolumn{8}{|c|}{ Maximum error [ppm] } \\
\hline 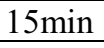 & 66 & 67 & 64 & 65 & 65 & 66 & 64 & 64 \\
\hline $30 \mathrm{~min}$ & 83 & & 85 & 81 & 85 & 83 & 85 & 84 \\
\hline ग & 84 & 79 & 89 & 83 & 87 & 80 & 88 & 86 \\
\hline $1 \mathrm{~h}$ & 98 & 96 & 98 & 92 & 98 & 92 & 98 & 86 \\
\hline 21 & 147 & & 146 & 123 & 147 & 124 & 147 & 124 \\
\hline & 166 & & 166 & 121 & 167 & 122 & 166 & 135 \\
\hline & 201 & 159 & 246 & 171 & 240 & 173 & 244 & 174 \\
\hline 1 day & 183 & 123 & 230 & 132 & 223 & 139 & 228 & 110 \\
\hline
\end{tabular}

Table 9. Prediction errors for $\mathrm{CO}_{2}$-models using 12-day datasets. The relative low and high prediction errors are coloured in green and red respectively.

\begin{tabular}{|c|c|c|c|c|c|c|c|c|}
\hline & \multicolumn{8}{|c|}{ RMSE [ppm] } \\
\hline 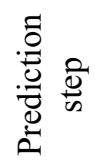 & $\begin{array}{l}0 \\
\frac{0}{0} \\
\dot{0}\end{array}$ & $\frac{\overline{0}}{\frac{0}{0}}$ & $\frac{\infty}{\frac{0}{0}}$ & $\begin{array}{l}\frac{\pi}{\infty} \\
\frac{0}{0} \\
\sum \\
\Sigma\end{array}$ & $\frac{a}{\frac{0}{0}}$ & $\frac{\pi}{\frac{\sigma}{0}}$ & $\begin{array}{l}0 \\
\overline{0} \\
\frac{0}{0} \\
\Sigma\end{array}$ & $\begin{array}{l}\frac{\pi}{0} \\
\frac{1}{0} \\
\frac{0}{2}\end{array}$ \\
\hline $15 \mathrm{~min}$ & & & 14 & 14 & 14 & 14 & 14 & 14 \\
\hline & & & - & 8 & 19 & 18 & 19 & 18 \\
\hline $45 \mathrm{~min}$ & 23 & 23 & 23 & 23 & 23 & 23 & 23 & 23 \\
\hline $1 \mathrm{~h}$ & & & 28 & 27 & 27 & 27 & 28 & 27 \\
\hline $2 \mathrm{~h}$ & 40 & 38 & 41 & 39 & 41 & 39 & 41 & 40 \\
\hline $4 \mathrm{~h}$ & & & 64 & 57 & 63 & 57 & & 61 \\
\hline $12 \mathrm{~h}$ & 91 & 77 & 109 & 81 & 105 & 81 & 109 & 89 \\
\hline 1 day & & 4 & 126 & 72 & 118 & 70 & 126 & 71 \\
\hline & \multicolumn{8}{|c|}{ Maximum error [ppm] } \\
\hline $15 \mathrm{~min}$ & 70 & 68 & 72 & 69 & 71 & 68 & 72 & 70 \\
\hline $30 \mathrm{~min}$ & 94 & & 97 & 93 & 96 & 92 & 91 & 96 \\
\hline $45 \mathrm{~min}$ & 117 & & 122 & & 121 & & 121 & 120 \\
\hline $1 \mathrm{~h}$ & 129 & 136 & 124 & 134 & 125 & 133 & 124 & 127 \\
\hline $2 \mathrm{~h}$ & 178 & 175 & 187 & 169 & 184 & 169 & 187 & 165 \\
\hline $4 \mathrm{~h}$ & 265 & 227 & 274 & 210 & 272 & 213 & 274 & 219 \\
\hline $12 \mathrm{~h}$ & 253 & 253 & 278 & 230 & 269 & 237 & 281 & 212 \\
\hline 1 day & 305 & 249 & 355 & 241 & 338 & 244 & 355 & 216 \\
\hline
\end{tabular}

\subsubsection{Impact changing conditions}

The applicability of model 6 using 5-day data during different conditions is determined by the white noise test. Figure 4 shows the ACF and CP for both winter and summer data. The white noise test is passed for the summer data, while the $95 \%$ confidence boundaries are exceeded with the winter data meaning the residuals cannot be categorized as white noise. This could mean the reference week of the occupancy matches the real occupancy better during the summer than winter. In contrast to the temperature models, no peaks can be determined on the residuals of the $\mathrm{CO}_{2}$-models.
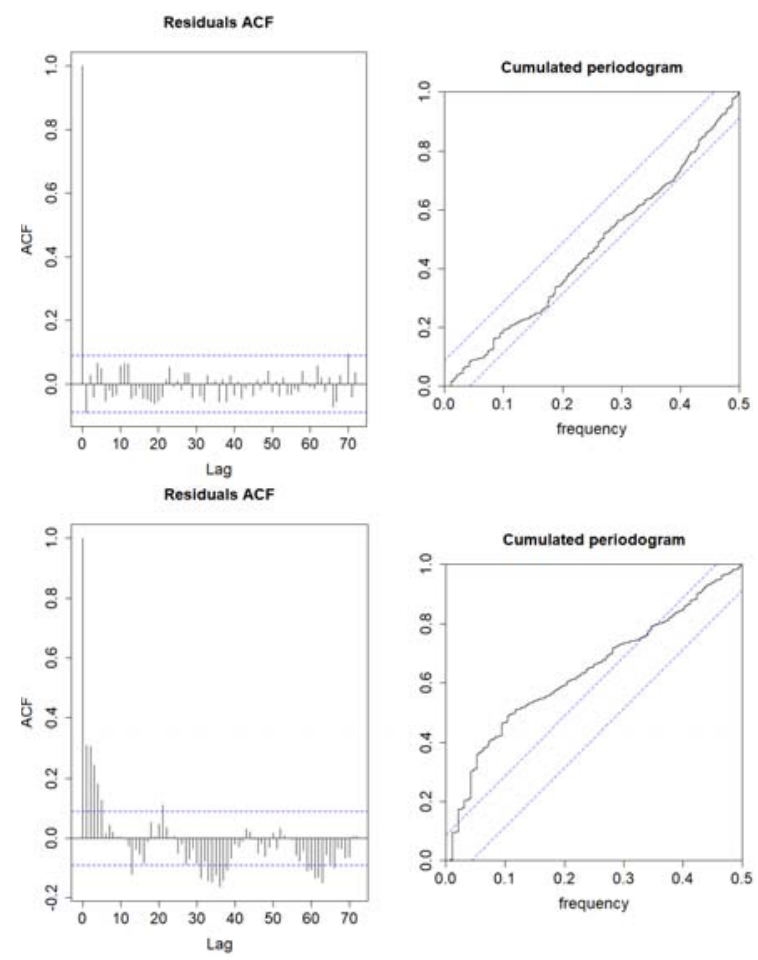

Figure 4. ACF and CP for model 6 validated with summer (above) and winter (below) data

\subsubsection{Prediction horizon}

Model 6 with a 5-day dataset is determined as the preferred $\mathrm{CO}_{2}$-model (see Table 8). In contrast to the temperature models, the absolute errors vary significantly with different prediction steps. Maximum prediction errors lower than the sensor accuracy of $70 \mathrm{ppm}$ can only be obtained with the prediction step of 15 minutes. In literature [5], [11] $\mathrm{CO}_{2}$-models are often validated based on the RMSE. In this case a prediction horizon of $4 \mathrm{~h}$ would be acceptable based on the RMSE. Nevertheless, this paper determines the accuracy of $\mathrm{CO}_{2}$-models mainly on maximum errors, leading to a short prediction horizon of 15 minutes. A higher order $\mathrm{CO}_{2}$-model could potentially extend the acceptable prediction horizon [12].

\section{Conclusions and future work}

This paper presents guidelines for grey-box model identification of predictive temperature and $\mathrm{CO}_{2-}$ models. The guidelines are determined by the results 
obtained from the identification, evaluation and validation of multiple grey-box models for an all-air HVAC-system in a landscaped office of a case study building. Attention should be given in generalising following guidelines since they are based on just one case study building.

A third-order model using 5-day datasets obtained the most accurate temperature predictions with an acceptable prediction horizon of maximum 1 day. Implementing the indoor temperature of one neighbouring zone strongly enhanced the prediction accuracy of the models. In contrast, the implementation of an occupancy parameter showed higher prediction errors, which could be caused by inaccurate measurements of the occupancy. Using accurate occupancy measurements could lead to improved prediction accuracies. Due to the orientation of the tested zone and the lack of solar irradiance measurements at the façade, the temperature models neglect the heat production due to the solar irradiance, which makes the temperature models not suitable during sunny periods.

The simplest $\mathrm{CO}_{2}$-model is preferred and achieves accurate predictions for a short prediction horizon of 15 minutes. More accurate measurements of the occupancy could extend the acceptable prediction horizon. Including the infiltration rate only delivers no or marginal prediction accuracy benefits over the base model. The method of implementing the influence of the neighbouring zones by the neighbouring occupancy is not accurate enough to obtain lower prediction errors. Furthermore, the effect of implementing the $\mathrm{CO}_{2}$ concentrations of the neighbouring zones in the greybox models on the prediction accuracy should be investigated.

The usage of 5-day datasets is preferred for both model types due to the shorter monitoring period, easier parameter convergence and mostly higher prediction accuracy. The use of 12-day datasets is only favoured for temperature models when an accurate estimation of the building's thermal inertia is needed. This means that the use of 12-day datasets is recommended for implementing a MPC, since it will predict the temperature decay more accurately during unconditioned periods, e.g., weekends and holidays.

Determining the most suitable model complexity based on the model's prediction accuracy is preferred over the likelihood ratio test, since the model's accuracy gives a more nuanced result.

Further research is needed to study the usability of temperature models during sunny periods. Furthermore, the effect of a more accurate occupancy measurement method on the models' prediction accuracy should be investigated. A next step should be to implement the identified models into a real predictive control system. To conclude, more research needs to be done in other case studies in order to generalize the results and guidelines.

\section{Acknowledgments}

The authors would like to acknowledge Bruno Motten, Tom Geens and the employees of the studied offices for their cooperation with this research and LEUVEN COOL Leuven.cool (in which data handling and informed consent protocol has been approved by the KU Leuven Social and Societal Ethics Committee under file number G-2019 06 1674) for providing weather data.

\section{References}

[1] K. Mařík, J. Rojíček, P. Stluka, and J. Vass, "Advanced HVAC Control: Theory vs . Reality," in IFAC Proceedings Volumes, 2011, vol. 44, no. 1, pp. 3108-3113.

[2] M. Killian and M. Kozek, "Ten questions concerning model predictive control for energy efficient buildings," Build. Environ., vol. 105, pp. 403-412, 2016.

[3] P. Bacher and H. Madsen, "Identifying suitable models for the heat dynamics of buildings," Energy Build., vol. 43, no. 7, pp. 1511-1522, 2011.

[4] H. Madsen et al., "Report of Subtask 3, part 2: Thermal performance characterisation using time series data - statistical guidelines," 2015.

[5] B. Merema, H. Breesch, and D. Saelens, "Comparison of model identification techniques for MPC in all-air HVAC systems in an educational building," E3S Web Conf., vol. 111, 2019.

[6] Q. Carton, "Modelidentificatie voor een gebouw en installatie voor een voorspellende regeling van de verwarming en ventilatie," KU Leuven, Ghent Technology Campus, 2020.

[7] B. Merema, M. Delwati, M. Sourbron, and H. Breesch, "Demand controlled ventilation (DCV) in school and office buildings: Lessons learnt from case studies," Energy Build., vol. 172, pp. 349-360, 2018.

[8] KU Leuven, KMI, Leuven2030, and Leuven, "Leuven.cool." https://leuven.cool/ (accessed Sep. 22, 2020).

[9] CTSM-R Development Team, "Continuous Time Stochastic Modeling in R.” 2018.

[10] G. Mustafaraj, G. Lowry, and J. Chen, "Prediction of room temperature and relative humidity by autoregressive linear and nonlinear neural network models for an open office," Energy Build., vol. 43, no. 6, pp. 1452-1460, 2011.

[11] M. Macarulla, M. Casals, M. Carnevali, N. Forcada, and M. Gangolells, "Modelling indoor air carbon dioxide concentration using grey-box models," Build. Environ., vol. 117, pp. 146-153, 2017.

[12] A. Pantazaras, S. E. Lee, M. Santamouris, and J. Yang, "Predicting the CO2 levels in buildings using deterministic and identified models," Energy Build., vol. 127, pp. 774-785, 2016. 